University of Nebraska - Lincoln

DigitalCommons@University of Nebraska - Lincoln

Captive Supplies and Cash Market Prices for Fed Cattle: The Role of Delivery Timing Incentives

John R. Schroeter

lowa State University

Azzeddine Azzam

University of Nebraska-Lincoln, Aazzam1@unl.edu

Follow this and additional works at: https://digitalcommons.unl.edu/ageconfacpub

Part of the Agricultural and Resource Economics Commons

Schroeter, John R. and Azzam, Azzeddine, "Captive Supplies and Cash Market Prices for Fed Cattle: The Role of Delivery Timing Incentives" (2004). Faculty Publications: Agricultural Economics. 102.

https://digitalcommons.unl.edu/ageconfacpub/102

This Article is brought to you for free and open access by the Agricultural Economics Department at DigitalCommons@University of Nebraska - Lincoln. It has been accepted for inclusion in Faculty Publications: Agricultural Economics by an authorized administrator of DigitalCommons@University of Nebraska - Lincoln. 


\title{
Captive Supplies and Cash Market Prices for Fed Cattle: The Role of Delivery Timing Incentives
}

\author{
John R. Schroeter \\ Department of Economics, Iowa State University, 260 Heady Hall, \\ Ames, IA 50011-1070. E-mail: johns@iastate.edu
}

Azzeddine Azzam

Department of Agricultural Economics, University of Nebraska, 103E H. C. Filley Hall, Lincoln, NE 68583-0922. E-mail: aazzam@unlnotes.unl.edu

\begin{abstract}
The use of non-cash methods of procuring fed cattle for slaughter has led to concern about the effect of these so-called "captive" supplies on cash market prices. Some empirical evidence suggests that there is a negative short-run relationship between the two: Cash market prices tend to be low in weeks in which captive supply shipments are high. We advance a different perspective on the relationship between captive deliveries and cash prices, arguing that the incentives that influence cattle delivery-scheduling decisions could lead to a negative relationship, not between the contemporaneous levels of captive shipments and price, but between the volume of captive deliveries, on the one hand, and an ex ante expectation of a week-to-week price change, on the other. Econometric testing provides some evidence of this empirical regularity in the cattle procurement activities of four large packing plants in Texas in the mid-1990s.
\end{abstract}

\section{Introduction}

In procuring fed cattle for slaughter, beef-packing firms rely, to a significant degree, on non-cash methods commonly known as "captive" supplies and typically defined to include marketing agreements, forward contracts, and packerfeeding of cattle. ${ }^{1}$ Growth in the relative importance of captive supply sources gives rise to a question of significant interest to individuals and firms engaged in the cattle business, and to government policy makers charged with the responsibility of overseeing the operation of livestock markets: What effect does the use of non-cash procurement methods have on cash market prices for fed cattle?

\footnotetext{
${ }^{1}$ All of these arrangements share the common feature that the cattle acquired via non-cash methods are committed to the packer at least two weeks in advance of slaughter, unlike cattle purchased by conventional "cash," or "spot," market means that are normally delivered to the plant within about one week of purchase. In 1999, 23.6\% of steer and heifer slaughter by the 15 largest packers represented captive supply cattle (USDA, GIPSA, 2002.)
} 
One important step in answering this question is the characterization of the empirical relationship between captive supplies and cash market prices. There are several papers in the literature reporting evidence of a negative relationship: Loosely speaking, fed cattle prices in regional markets tend to be low in weeks or months in which the region's captive supply delivery volume is high. ${ }^{2}$ Needless to say, however, the existence of this kind of negative correlation does not necessarily imply a causal linkage through which increases in the use of non-cash procurement methods cause the cash market price to fall. To determine whether an observed empirical regularity is a reflection of a causal relationship (in one direction or the other), one must more closely investigate the economic mechanism underlying it. In our judgment, more work in this direction is needed. ${ }^{3}$

This report does not provide a complete explanation of the dynamics of captive supply shipments and cash price. Instead, this report is similar in spirit to other studies that have sought, simply, to characterize the pattern of covariation between these two variables. While other studies have focused on the correlation between the contemporaneous levels of captive shipments and price, our work addresses a different aspect of the relationship. The empirical regularity that we investigate involves the volume of marketing agreement or forward contract deliveries in week $t$, say, and an ex ante expectation of the change in cash price between weeks $t-1$ and $t$. In Captive Supply Delivery-Scheduling Decisions, we present two simple models of packers' and feeders' delivery-scheduling decisions that suggest that captive shipments and expected price changes might be negatively correlated. These models will build on certain key institutional features of captive supply arrangements that will be described first in Some Institutional Features of Captive Supply Arrangements. Some econometric testing of our models' predictions will be undertaken in Empirical Testing using a data set collected by the Grain Inspection, Packers and Stockyards Administration (GIPSA) of the USDA. It provides a nearly complete record of the cattle procurement activities of four large fed cattle slaughter plants in the Texas Panhandle from early February 1995 through mid-May 1996. ${ }^{4}$ Estimation results provide some support, though not conclusive support, for the predictions of the delivery-timing models. Whether the amply documented negative correlation between the levels of captive shipments and price could simply be an artifact of delivery-scheduling decisions is a question that we leave for further research.

\footnotetext{
${ }^{2}$ Examples of studies of this kind include Elam (1992), Hayenga and O'Brien (1992), Schroeder, Jones, Mintert, \& Barkley (1993), and Schroeter and Azzam (1999).

${ }^{3}$ We know of two theoretical studies (Azzam 1998; Love \& Burton, 1999) and one experimental simulation study (Ward, Koontz, Dowty, Trapp, \& Peel, 1999) of the effect of vertical coordination of input supplies on price in the residual cash market. Those studies, using models that are essentially static in nature, address the question of how the cash market price would be affected by a change in the share of input supplies procured through non-cash sources. Most of the empirical studies correlate cash prices with week-to-week variation in captive supply delivery volume. But the origins of the weekly variation in captive shipments are more complex in reality than in the theoretical models. Observed delivery volumes vary from week-to-week partly due to past decisions about the volume of captive supplies to contract for a given month, say, and partly due to more recent decisions about when, within that month, to schedule delivery. Because these two sources of variation are confounded in the data, it is not clear whether the negative empirical relationship has any bearing on the predictions of the theoretical models.

${ }^{4}$ Schroeter and Azzam (1999) provide a detailed description of the GIPSA-Texas Panhandle data. This report extends the analysis undertaken in section VIII.2 of that report.
} 


\section{Some Institutional Features of Captive Supply Arrangements}

Cattle procured by non-cash methods include marketing agreement cattle, forward contract cattle, and packer-fed cattle. In the GIPSA data collected for the Texas Panhandle study, marketing agreements were by far the most important non-cash procurement method, accounting for $73.1 \%$ of all non-cash cattle, and $21.0 \%$ of all cattle, slaughtered by the four plants during the period of investigation. Marketing agreements are standing arrangements between feeder and packer for transactions in fed cattle. The written agreements are often relatively vague with respect to the volume of cattle to be shipped over a given time period, sometimes mentioning an approximate number per year. The agreements stipulate that the cattle will be priced according to a formula. Generally speaking, formulas involve a base price, applicable to cattle of given quality characteristics (typically defined in terms of a given yield grade, quality grade, and carcass weight range), and a system of premia and discounts that are used to adjust the base price when the characteristics of delivered cattle deviate from those of the base carcass. Base prices can be set in a variety of ways, depending on the formula. Nine formulas accounted for virtually all of the marketing agreement cattle purchased by the four plants in the Texas Panhandle sample. In all of these formulas, the base price is tied, in one way or another, to cash market prices paid the week prior to delivery of the marketing agreement cattle. For example, in five of the formulas, the base price is set at the level of a USDA Agricultural Marketing Service (AMS)-reported price for fed cattle in the relevant regional market the week prior to delivery. In the remaining four formulas, the base price is set at the level of a quality-adjusted average price paid by the packer for cash market cattle slaughtered during the week of delivery of the marketing agreement cattle. But since the typical delivery lag for cash market cattle is approximately one week, this arrangement, too, ties the base price to the previous week's cash market price. ${ }^{5}$

The terms of marketing agreements typically give the feeder discretion over the number of cattle to be delivered each week. Each week, the feeder notifies the packer of the number of head planned for delivery two weeks hence. ${ }^{6}$ Once the volume of marketing agreement deliveries for a given week is set, the packer usually has discretion over the specific day or days of the week upon which delivery will be made.

Forward contract cattle were the second most important non-cash source of fed steers and heifers in the GIPSA-Texas Panhandle study. This procurement method accounted for $18.2 \%$ of all non-cash cattle, and $5.2 \%$ of all cattle, slaughtered by the four plants during the period of investigation. Forward contracts call for the feeder to deliver a specific number of cattle to the packer within a specific month. The scheduling of deliveries across weeks and days within the month is left to the packer, however. Once the decision is made to deliver a certain number of cattle in a given week, there can be a time lag attributable to delays in arranging transportation. The GIPSATexas Panhandle data suggest that the number of forward contract cattle delivered in a given week is normally decided either one or two weeks in advance.?

${ }^{5}$ For spot market lots of cattle in the GIPSA-Texas Panhandle data, the distribution of the lag, in days, between purchase and delivery has a mean of 6.98 and a standard deviation of 3.28.

${ }^{6}$ Appendix B of Schroeter and Azzam (1999) substantiates this claim with some evidence from company documents and interviews with feedlot personnel.

${ }^{7}$ For forward contract lots in the GIPSA-Texas Panhandle data, the distribution of the number of days from the scheduling date until the kill date has a mean of 11.88 days and a standard deviation of 7.98 days. 
The data identify lots of cattle purchased on forward contracts but are silent on the specific terms of the contracts. Certainly, the vast majority (perhaps even all) of the forward contract cattle in the sample were purchased on basis forward contracts. Ward, Koontz, and Schroeder (1996) describe this contract form:

A packer bids a futures market basis for the month cattle are expected to reach slaughter weight and finish. The feeder then has the option of determining when to price the cattle (i.e., select a futures market price). From that futures market price, a cash selling price is computed, based on the agreed-upon basis...For example, assume that after the basis contract is signed, a cattle feeder believes the futures market price for the specified contract month has peaked. The cattle feeder notifies the packer and chooses the then-current futures market price, thereby also determining the cash sale price, based on the previously agreed basis bid.

Thus, by the time the delivery month arrives and the packer comes to the point of deciding how to allocate the contract's number of head across the delivery month's weeks, forward contract cattle represent a fixed-price supply source.

"Packer-fed" cattle are owned by the packer while the cattle are on feed. In the GIPSA-Texas Panhandle data, packer-fed cattle constituted a relatively small non-cash procurement source, accounting for only $8.6 \%$ of all non-cash cattle, and only $2.5 \%$ of all cattle, slaughtered by the four plants during the period of investigation. Because it is a relatively insignificant captive supply source in this data set, packer feeding of cattle will not be further addressed in this analysis. ${ }^{8}$

\section{Captive Supply Delivery-Scheduling Decisions}

This section presents simple models of the scheduling of delivery for marketing agreement and forward contract cattle. Consistent with key institutional features of these marketing arrangements, the marketing agreement scheduling model has the feeder in the role of decision-maker with delivery volume determined two weeks in advance. In our model of forward contract scheduling, the packer decides the timing of deliveries either one or two weeks in advance. It is important to note that these models provide a partial analysis insofar as they analyze the timing of delivery for a given overall degree of reliance on the captive supply source and a given price process, but do not consider how or whether these delivery scheduling decisions might feed back into the determination of cash market price and quantity. ${ }^{9}$

\subsection{Marketing Agreement Delivery Timing Model}

Each lot of cattle owned by a marketing agreement feeder is characterized by the week in which the cattle are expected to reach optimal marketing condition. In our discussion, we will describe this as the week in which the cattle are "ready" to be delivered and we will use the term " $t$-ready cattle" to refer to the entire cohort of

\footnotetext{
${ }^{8}$ Packer feeding of cattle continues to play a relatively minor role at the national level as well. For example, in 1998 for the 15 largest packers, deliveries of packer-fed steers and heifers were only $3.7 \%$ of total steer and heifer slaughter (USDA,GIPSA,2002).

${ }^{9}$ A complete equilibrium model of these phenomena is needed but is a challenging goal beyond the scope of this report.
} 
a feeder's cattle, typically including several lots, that are ready for week $t$ delivery. Delivery of cattle before or after the week in which they are ready is costly to the feeder. For example, delivering cattle early, although it would hasten the receipt of sales revenue and save feed cost, would entail a price discount assessed against cattle sold short of optimal market weight and finish. Delivering cattle late could incur a quality discount too, as well as the costs associated with additional feed and deferred revenue. Early or late delivery would alter the timing of the purchase of replacement feeder cattle and this might also entail costs, depending on how feeder cattle prices are changing over time. Nonetheless, it may be in the interest of the feeder to deliver cattle either before or after the week in which they are ready if, by doing so, the feeder could take advantage of a favorable price movement. ${ }^{10}$ The wisdom of this kind of intertemporal arbitrage in delivery scheduling will be determined by a comparison of the expected price change with the aforementioned costs, "arbitrage costs," of early or late delivery. ${ }^{11}$

The magnitude of arbitrage costs is affected by several factors. Some factors, like current feed prices, interest rates, and feeder cattle prices, are relatively generic in that they affect the arbitrage costs of all lots of cattle more or less equally. Other factors, primarily the current condition of the cattle, are "specific" in that they affect arbitrage costs on a lot-by-lot or even animal-by-animal basis. In general, arbitrage costs for $t$-ready cattle are greater the further the proposed delivery week is from week $t$. To simplify the analysis, we assume that the nature of arbitrage costs is such that feasible delivery options are limited in the following way. For any given animal, there are only two feasible delivery weeks: the week that is best suited for delivery and either one week before or one week after. Arbitrage costs for all other delivery options are assumed to be prohibitive. Thus, within a cohort of $t$-ready cattle, some cattle could be delivered one week early, in week $t-1$, and some other cattle could be delivered one week late, in week $t+$ 1. This simplifying assumption amounts to an implicit restriction on the distribution of arbitrage costs within the cohort of cattle. ${ }^{12}$

Consider the problem faced by a marketing agreement feeder trying to determine, at week $t-2$, the number of head of cattle to be delivered in week $t$. The feeder's week $t$ - 1 delivery numbers were irrevocably fixed in week $t-3$, and it is possible that that decision committed the feeder to week $t-1$ delivery of only some of his $t$ - 1-ready cattle. The remaining cattle; numbering $n_{\mathrm{t}-1}$, say; would then be delivered in week $t$. Let $N_{t}$ represent the number of the feeder's $t$-ready

${ }^{10}$ Although we have not conducted our own survey of market participants to inquire about their delivery-scheduling decision process, there is limited anecdotal evidence that marketing agreement feeders are aware of the incentives created by future price changes and even employ consultants to help them forecast these changes. Both Hausman (2000) and Schroeder (2000) comment on this in written statements submitted in conjunction with a September 2000 USDA public Forum on captive supplies.

${ }^{11}$ Some arbitrage costs, like the additional feed costs of late delivery, correspond to out-of-pocket expenditures. Others, like price discounts for sub-optimal quality, are implicit opportunity costs. For simplicity, we think of all arbitrage costs on an expenditure-equivalent basis. For example, sustaining a quality discount can be viewed as having to "pay back" a portion of the optimal-quality sale price.

12 To say that arbitrage costs are "prohibitive" for delivery two weeks early (for example) means that they exceed the maximum expected price decline over a two-week interval. Thus, our simplifying assumption really amounts to implicit restrictions on the joint distribution of arbitrage costs and week-to-week price changes. Without this simplifying assumption, our analysis of the delivery timing decision would have to take account of the fact that one potential advantage of a one-week deferral of delivery is that it provides time to gather more data to inform the decision about a possible two-week deferral. With our simplifying assumption, this option value does not arise. 
cattle that remain available at week $t-2 .{ }^{13}$ Let $N_{t+1}$ be the number of the feeder's $t+1$-ready cattle. The starting point for the determination of the feeder's delivery numbers for week $t$ will be $n_{t-1}$ plus $N_{t^{\prime}}$ with two possible adjustments: Delivery of some of the $N_{t}$ available $t$-ready cattle might be deferred to week $t+1$, or delivery of some of the $N_{t-1} t+1$-ready cattle might be moved up to week $t$.

Because arbitrage costs of early or late delivery vary within any cohort of cattle, it is natural to model them as realizations of a random variable. Let $C_{e}$ be the (random) arbitrage cost of early delivery within the feeder's cohort of $N_{t-1} t+$ 1-ready cattle. Let $F_{e^{\prime} t+1}($.$) denote the distribution function for this random vari-$ able so that, for any $c_{e}>0, F_{e^{\prime} t+1}\left(c_{e}\right)$ is the proportion of the $N_{t-1} t+1$-ready cattle with $C_{e} \leq c_{e}$. Because arbitrage costs are non-negative, $F_{e^{\prime} t+1}\left(c_{e}\right)$. for any $c_{e} \leq 0$ and, because $F_{e^{\prime} \mathrm{t}+1}($.$) is a distribution function, F_{e^{\prime} \mathrm{t}+1}^{\prime}\left(c_{e}\right) \geq 0$ for all $c_{e} \geq 0$. Likewise, let $C_{1}$ denote the (random) cost of late delivery within the cohort of $N_{t} t$-ready cattle and let $F_{l^{\prime} t}($.) denote the distribution function for this random variable. Then, for any $c_{l}>0, F_{l^{\prime} \mathrm{t}}\left(c_{l}\right)$ is the proportion of the $N_{t} t$-ready cattle having $C_{l} \leq c_{l}$. As before, $F_{l}, t\left(c_{l}\right)=0$ for any $c_{l} \leq 0$ and $F^{\prime}{ }^{\prime}{ }_{t}\left(c_{l}\right) \geq 0$ for all $c_{l}>0$.

The feeder, in week $t-2$, forms a forecast of the price change that will occur between weeks $t-1$ and $t: E_{t-2}\left[p_{t}-p_{t-1}\right]$. Suppose that this expected price change is positive. Assuming risk neutrality, it would then be in the feeder's interest to shift some $t$-ready cattle from week $t$ delivery, in which they would receive price $p_{t-1}$, to week $t+1$ delivery, in which they would receive the higher price, $p_{t}{ }^{14}$ The cattle that could be profitably arbitraged in this way are those for which arbitrage costs are no bigger than the expected price change, and the number of such cattle is $F_{l^{\prime} \mathrm{t}}\left(E_{t-2}\left[p_{t}-p_{t-1}\right]\right) N_{t}$.

Next, suppose that the forecast of the price change is negative+ In this case, early delivery of some $t+1$-ready cattle would be appropriate to take advantage of the relatively high price $\left(p_{t-1}\right)$ paid to cattle delivered in week $t$ prior to the expected price decline. Cattle could be profitably arbitraged if $C_{e} \leq-E_{t-2}\left[p_{t}-p_{t-1}\right]$, and the number of $\mathrm{t}+1$-ready cattle meeting this requirement is $F_{e^{\prime} t+1}\left(-E_{t-2}\left[p_{t}-p_{t-}\right.\right.$ $\left.\left.{ }_{1}\right]\right) N t+1$. Finally, the total number of cattle that the feeder will commit to deliver in week $t, q m_{t}$, is given by

$$
q m_{t}=n_{t-1}+\left(1-F_{l, t}\left(E_{t-2}\left[p_{t}-p_{t-1}\right]\right)\right) N_{t}+F_{e, t+1}\left(-E_{t-2}\left[p_{t}-p_{t-1}\right]\right) N_{t+1} .
$$

Note that the second term in the expression for $q m_{t}$ is simply $N_{t}$ if $E_{t-2}\left[p_{t}-p_{t-1}\right] \leq 0$ and the third term is zero for $E_{t-2}\left[p_{t}-p_{t-1}\right]>0$. Differentiating:

$$
\begin{array}{r}
\partial q m_{t} / \partial\left(E_{t-2}\left[p_{t}-p_{t-1}\right]\right)=-F_{e, t+1}^{\prime}\left(-E_{t-2}\left[p_{t}-p_{t-1}\right]\right) N_{t+1} \text { if } E_{t-2}\left[p_{t}-p_{t-1}\right] \leq 0 \\
o r-F_{l, t}^{\prime}\left(E_{t-2}\left[p_{t}-p_{t-1}\right]\right) N_{t} \text { if } E_{t-2}\left[p_{t}-p_{t-1}\right]>0 .
\end{array}
$$

In either case, $\partial q m_{t} / \partial\left(E_{t-2}\left[p_{t}-p_{t-1}\right]\right) \leq 0$ : Marketing agreement delivery volume in week $t$ is inversely related to the expectation, formed in week $t-2$, of the price change from week $t-1$ to week $t$.

\footnotetext{
${ }^{13}$ Just as the delivery of some $t$-1-ready cattle might have been delayed to week $t$, some of the $t$-ready cattle might have been committed, in week $t-3$, to be delivered in week $t-1$. Thus, we define $N_{t}$ to include only those $t$-ready cattle that are still available for week $t$ delivery.

14 The marketing agreement formula price for cattle delivered in week $t$ is tied to $p_{t-1}$ through the connection between the formula's "base price" and spot prices in week $t-1$. In this analysis, we assume that the price paid to marketing agreement cattle delivered in week $t$ is simply $p_{t-1}$.
} 


\subsection{Forward Contract Delivery Timing Model}

To help illuminate factors affecting the timing of contract cattle delivery, we resort to a simple two-period analysis, much as we did in the model of marketing agreement delivery timing. Imagine a packer with cattle under contract for delivery in weeks $t$ or $t+1$. The total number of cattle under contract consists of $N_{t} t$-ready and $N_{t+1} t+1$-ready cattle. The packer's total procurement targets for weeks $t$ and $t+1$ are $Q_{t}$ and $Q_{t+1}$ head of cattle respectively. ${ }^{15}$ In each of the two weeks, any shortfall of contract deliveries relative to these targets will be made up with deliveries of spot market cattle purchased the week prior to delivery.

As a natural counterpart to our assumptions in the model of marketing agreement delivery timing, we assume here that the packer could opt to order delivery of some of the contract cattle in a week before or after the week in which they are ready. This would involve a cost, however, due to the sub-optimal quality of cattle delivered "off-schedule." Our ad hoc treatment of these costs is to model them as an increasing, convex function of the number of cattle delivered off-schedule: $c(q)$ where $q$ denotes the volume of off schedule deliveries and $c^{\prime}(q)>0, c^{\prime \prime}(q)>0$ for all $q \geq 0$. Costs of off-schedule delivery would obviously be increasing in the volume of cattle delivered early or late. The assumption of a positive second derivative reflects the fact that, within the cohort of $t$-ready cattle, for example, different lots, or different animals within any given lot, would sustain different degrees of quality degradation as a result of late delivery. Because the first lots chosen for delivery postponement would be those that could be arbitraged at least cost, the per-head costs of late delivery would increase as the volume of late deliveries increases. ${ }^{16}$

For $\tau=t$ or $t+1$, let $q c_{\tau}$ denote the number of contract deliveries ordered for week $\tau$. Since contract deliveries for the two weeks must total $N_{t}+N_{t+1}$, we have $q c_{t+1}=N_{t}+N_{t+1}-q c_{t}$. Spot purchases will make up the balance of procurement targets in each week:

$$
\begin{aligned}
q s_{t} & =Q_{t}-q c_{t} \text { and } \\
q s_{t+1} & =Q_{t+1}-q c_{t+1} \\
& =Q_{t+1}-N_{t}-N_{t+1}+q c_{t},
\end{aligned}
$$

where $q s_{\tau}$ denotes spot market purchases in week $\tau-1$ for delivery in week $\tau$. If the packer orders week $t$ delivery of more than the number of $t$-ready cattle under contract, so that $q c_{t}>N_{t}$, the cost of early delivery of some of the $t+1$-ready cattle is $c\left(q c_{t}-N_{t}\right)$. On the other hand, if delivery of some of the t-ready cattle is postponed, so that $q c_{t}<N_{t}$, the cost of late delivery is $c\left(N_{t}-q c_{t}\right)$. In either case, costs of off-schedule delivery are captured by $c\left(\left|6 q c_{t}-N_{t}\right|\right)$.

Assuming a two-week lag between scheduling and delivery of contract cattle, the delivery timing decision will be made in week $t-2$. In view of the nature of forward contracts, the acquisition cost of the contract cattle will, by then, be sunk.

${ }^{15}$ For simplicity, we treat these procurement "targets" as predetermined in this analysis focusing on the packer's decision regarding procurement method. In a more complete model, total procurement would also be treated as endogenous.

${ }^{16}$ For simplicity in the exposition, we treat the costs of early and late delivery symmetrically. Little would change if we allowed asymmetric costs of off-schedule delivery. 
So the packer's objective is to schedule contract deliveries to minimize the expected spot market costs and off-schedule delivery costs of meeting procurement targets for weeks $t$ and $t+1$ :

$$
\min _{w . r . t . q c_{t}}\left(Q_{t}-q c_{t}\right) E_{t-2}\left[p_{t-1}\right]+\left(Q_{t+1}-N_{t}-N_{t+1}+q c_{t}\right) E_{t-2}\left[p_{t}\right]+c\left(\left|q c_{t}-N_{t}\right|\right)
$$

subject to $\max \left\{0, N_{t}+N_{t+1}-Q_{t+1}\right\} \leq q c_{t} \leq \min \left\{Q_{t}, N_{t}+N_{t+1}\right\}$. An interior solution with $q c_{t}>N_{t}$ must satisfy the first order condition

$$
E_{t-2}\left[p_{t}-p_{t-1}\right]+c^{\prime}\left(q c_{t}-N_{t}\right)=0
$$

which can hold only if $E_{t-2}\left[p_{t}-p_{t-1}\right]<0$ : It is optimal for the packer to deliver contract cattle ahead of schedule only when price is expected to decrease. An interior solution with $q c_{t}<N_{t}$ must satisfy the first order condition

$$
E_{t-2}\left[p_{t}-p_{t-1}\right]-c^{\prime}\left(N_{t}-q c_{t}\right)=0,
$$

which can hold only if $E_{t-2}\left[p_{t}-p_{t-1}\right]>0$ : It is optimal for the packer to postpone the delivery of contract cattle only when price is expected to increase+ Implicit differentiation of either first order condition yields the same result:

$$
\partial q c_{t} / \partial E_{t-2}\left[p_{t}-p_{t-1}\right]=-1 / c^{\prime \prime}\left(\left|q c_{t}-N_{t}\right|\right)<0 .
$$

Contract cattle deliveries in week $t$ are inversely related to the expectation, formed in week $t-2$, of $p_{t}-p_{t-1}$.

The forgoing analysis assumed that contract deliveries are scheduled two weeks in advance+ If the actual delay between scheduling and delivery is one week, the appropriately amended analysis would have returned a very similar result: Contract deliveries in week $t$ are inversely related to $E_{t-1}\left[p_{t}\right]-p_{t-1}$.

\section{Empirical Testing}

The models of the previous section yield the following hypothesis: The volume of marketing agreement or forward contract cattle delivered in a given week, week $t$, say, tends, other things equal, to be negatively correlated with a previously formed expectation of the change in price between weeks $t-1$ and $t$. The "other things equal" qualification is a reminder that many other factors influence feeders' and packers' decisions about the number of non-cash cattle to deliver in a given week and, to the extent possible, we should control for these factors in our regression-based tests of the hypothesis. Among these factors, for the case of marketing agreement cattle, are the generic factors affecting the arbitrage costs that feeders would incur as a result of off-schedule delivery. As noted in the previous section, these depend, to some extent, on variables such as feed and feeder cattle prices and interest rates. The Choice-Select spread is another generic determinant of arbitrage costs because it is reflective of the cost that feeders and packers would pay for the sub-optimal quality of off-schedule deliveries of non-cash cattle.

Other factors affecting delivery-scheduling decisions are specific to the individual feeder or packer. For example, a particular feeder's week $t-2$ decision about the number of head to deliver in week $t$ will be influenced by its number 
of $t$-ready cattle, and by its number of $t$ - 1-ready cattle (if any) for which delivery was deferred to week $t$. From a particular packer's point of view, the number of contract cattle to call in a given week depends, in large part, on its current inventory of contract cattle; that is, the total volume of cattle initially under contract for delivery at some time during the current month minus any that have already been delivered. These factors will tend to introduce autoregressive patterns in weekly delivery numbers, which we can control, to some extent, by incorporating lagged delivery volumes as explanatory variables.

The hypothesis will be tested using the following regression models, which will be estimated using the GIPSA-Texas Panhandle data:

$$
\begin{aligned}
Q M_{t}= & \alpha_{0}+\alpha_{1} E_{t-2}\left[p_{t}-p_{t-1}\right]+\alpha_{2} \operatorname{crnp}_{t-2}+\alpha_{3} f c p_{t-2}+\alpha_{4} r_{t-2} \\
& +\alpha_{5} \operatorname{cssp}_{t-2}+\sum_{j=1}^{k} \beta_{j} Q M_{t-j}+\varepsilon_{1 t} \\
Q C_{t}= & \alpha_{0}+\alpha_{1} E_{t-2}\left[p_{t}-p_{t-1}\right]+\alpha_{2} \operatorname{cssp}_{t-2}+\alpha_{3} r_{t-2}+\sum_{j=1}^{k} Q C_{t-j}+\varepsilon_{2 t} \\
Q C_{t}= & \alpha_{0}+\alpha_{1}\left(E_{t-1}\left[p_{t}\right]-p_{t-1}\right)+\alpha_{2} \operatorname{cssp}_{t-1}+\alpha_{3} r_{t-1}+\sum_{j=1}^{k} Q C_{t-j}+\varepsilon_{3 t}
\end{aligned}
$$

where $Q M_{t}\left(Q C_{t}\right)$ is the number of marketing agreement $\sim$ forward contract! cattle delivered to the four plants combined in week $t$. $p_{t}$ represents week $t^{\prime}$ s average spot market price of steers in the regional market. ${ }^{17} E_{s}\left[p_{\tau}\right]$ denotes the expectation, formed in week $s$, of week $\tau^{\prime}$ s value of price. $c r n p_{t}$ and $f c p_{t}$ are week $t^{\prime}$ s prices for cattle feed and feeder cattle in the Texas Panhandle region. $r_{t}$ is an interest rate in week $t$. $\operatorname{css} p_{t}$ is the Choice-Select spread for week $t$. The models' explanatory variables also include one or more lags of the dependent variable. The $\varepsilon_{i t} \mathrm{~s}$ are random error terms. With respect to the delivery of marketing agreement cattle, the hypothesis implies a negative value for $a_{1}$ in equation (1). Because there is some ambiguity about the representative lag between scheduling and delivery in the case of forward contract cattle, the implications here are not as sharp. In the event that the representative lag is 2 weeks, the hypothesis implies a negative value for $a_{1}$ in equation (2). If the delivery lag is closer to 1 week, we would expect a negative value for $a_{1}$ in equation (3).

To estimate equations (1), (2), and (3), we must first address the question of how decision makers will form their two-week-ahead forecasts of the week-toweek change in price $\left(E_{t-2}\left[p_{t}-p_{t-1}\right]\right)$ and their one-week-ahead forecast of price $\left(E_{t-1}\left[p_{t}\right]\right)$. One conventional approach to modeling expectations uses the series of fitted values from a regression of actual values of the variable to be forecast on a set of variables that are thought to be relevant to the determination of the forecast variable and were observable to decision makers in the week in which the forecast was formed. In that spirit, we posit the following two-week-ahead price change forecasting equation:

\footnotetext{
${ }^{17}$ More precise definitions of variables appear in the Appendix.
} 


$$
\begin{aligned}
p_{t}-p_{t-1}= & a_{0}+a_{1} p_{t-2}+a_{2} p_{t-3}+a_{3} p_{t-4}+a_{4} \Delta f p_{t-2}+a_{5} \text { val }_{t-2} \\
& +a_{6} r_{t-2}+a_{7} c f_{t-2}+a_{8} f c p_{t-2}+a_{9} c r n p_{t-2}+a_{10} c p l_{t-2}+a_{11} l c p l_{t}+\mu_{1 t}
\end{aligned}
$$

and the following one-week-ahead price forecasting equation:

$$
\begin{aligned}
p_{t}= & b_{0}+b_{1} p_{t-1}+b_{2} p_{t-2}+b_{3} p_{t-3}+b_{4} \Delta f p_{t-1}+b_{5} v a l_{t-1} \\
& +b_{6} r_{t-1}+b_{7} c f_{t-1}+b_{8} f c p_{t-1}+b_{9} c r n p_{t-1}+b_{10} c p l_{t-1}+b_{11} l c p l_{t}+\mu_{2 t},
\end{aligned}
$$

where, again, $p_{t}$ represents the region's average spot market price of cattle in week $t . \Delta f p_{t}$ is the change in the price of week $t^{\prime}$ ' "nearby" live cattle futures contract from the first reporting day of week $t-1$ to the first reporting day of week $t$. $v a l_{t}$ is the average box beef cutout value for week $t$. $c f_{t}$ is the number of cattle on feed in Texas feed yards in week $t$. $c p l_{t}$ is the number of cattle placed on feed in Texas feed yards during week $t$. $l c p l_{t}$ is a simple average of the values of $c p l_{s}$ for $s$ values corresponding to $20,21,22$, and 23 , weeks prior to week $t$. This variable is intended to provide a rough indication of the number of cattle that may be reaching market weight in feed yards serving the four plants in the GIPSA-Texas Panhandle study. ${ }^{18} r_{t}, c r n p_{t}$, and $f c p_{t}$ were defined previously. The $\mu_{\mathrm{it}}$ terms are random errors.

Equations (4) and (5) were estimated by ordinary least squares (OLS) using 67 weekly observations. ${ }^{19}$ Each equation was tested for serial correlation in the error term and the hypothesis of no serial correlation could not be rejected in either case. ${ }^{20}$ OLS regression results are reported in Tables 1 and 2.

In the analysis of equations (1), (2), and (3), $E_{t-2}\left[p_{t}-p_{t-1}\right]$ is taken to be the series of fitted values from OLS estimation of equation (4) and $E_{t-1}\left[p_{t}\right]$ is taken to be the series of fitted values from OLS estimation of equation (5).This approach to modeling expectation formation is subject to the customary criticisms. Few, if any, of the real market participants actually use an econometric model to develop their forecasts, so our approach appears to attribute to the decision-makers an unrealistically high degree of analytical ability. In reality, agents' expectations about the future path of price are based on an understanding of the market mechanism that is probably more intuitive than analytical. To discover agents' true expectations, one could imagine conducting an ongoing opinion survey that asked them to report their guesses about future price movements, but data of this nature are simply unavailable. So we must resort to some sort of proxy for agents' expectations. Presumably, the intuition upon which actual expectations is based reflects empir-

${ }^{18}$ Number of days on feed varies widely depending on the condition of cattle at placement and, to some extent, the season of the year. One hundred and fifty days (approximately 21 weeks) is a representative average figure with a range of about 120 days to about 180 days.

19 The GIPSA-Texas Panhandle data contain essentially complete records on the lots of cattle killed by the four plants during a 67-week time span from the week of February 5,1995 through the week of May 12,1996. Equations (4) and (5) were estimated over the samples required to generate the expectation proxies needed in equations (1), (2), and (3).

20 Testing for serial correlation in the errors of these equations is complicated by the presence of lagged dependent variables among the regressors. We used a procedure (Greene, 2000, section 13.5.3) that is a modification of the Breusch-Godfrey test. It involves regressing the residuals from OLS estimation on the original equation's explanatory variables and several lags of the residuals. A standard F-test of the null hypothesis that the coefficients of the lagged residuals are all zero amounts to a test of no serial correlation. 
Table 1. Results of Ordinary Least Squares Estimation of Equation (4), the Two-WeekAhead Price Change Forecasting Equation

\begin{tabular}{|c|c|c|c|}
\hline \multicolumn{2}{|c|}{$\begin{array}{l}\text { Dependent variable }=p_{t}-p_{t-1} \\
\text { F-stat }[P \text {-value }]=1.85[0.067]\end{array}$} & \multicolumn{2}{|c|}{$\begin{array}{l}\text { Number of observations }=67 \\
\qquad R^{2}=0.270\end{array}$} \\
\hline $\begin{array}{l}\text { Explanatory } \\
\text { variable }\end{array}$ & $\begin{array}{l}\text { Parameter } \\
\text { estimate }\end{array}$ & $\begin{array}{l}\text { Standard } \\
\text { error }\end{array}$ & $\begin{array}{l}\text { t-statistic for } \mathrm{H}_{0} \text { : } \\
\text { parameter }=0\end{array}$ \\
\hline Intercept & -5.7448 & 13.9907 & -0.41 \\
\hline$p_{\mathrm{t}-2}$ & -0.6257 & 0.1941 & -3.22 \\
\hline$p_{\mathrm{t}-3}$ & 0.5790 & 0.2165 & 2.67 \\
\hline$p_{\mathrm{t}-4}$ & -0.1178 & 0.1559 & -0.76 \\
\hline$\Delta f p_{t-2}$ & 0.1981 & 0.1869 & 1.06 \\
\hline val $_{t-2}$ & -0.0415 & 0.1204 & 0.34 \\
\hline$r_{t-2}$ & 1.0735 & 2.5808 & 0.42 \\
\hline$c f_{t-2}^{t-2}$ & 0.0016 & 0.0037 & 0.44 \\
\hline$f c p_{t-2}$ & 0.0874 & 0.1362 & 0.64 \\
\hline crnp $_{t-2}$ & 0.9642 & 0.9770 & 0.99 \\
\hline$c p l_{t-2}^{t-2}$ & 0.0120 & 0.0075 & 1.59 \\
\hline$l_{c p l} l_{t}$ & 0.0050 & 0.0152 & 0.33 \\
\hline
\end{tabular}

Note. Definitions of variables are provided in the Appendix.

Table 2. Results of Ordinary Least Squares Estimation of Equation (5), the One-WeekAhead Price Level Forecasting Equation

\begin{tabular}{|c|c|c|c|}
\hline \multicolumn{2}{|c|}{$\begin{array}{c}\text { Dependent variable }=p_{t} \\
\text { F-stat }[\mathrm{P} \text {-value }]=46.44[<0.0001]\end{array}$} & \multicolumn{2}{|c|}{$\begin{array}{l}\text { Number of observations }=67 \\
\qquad R^{2}=0.903\end{array}$} \\
\hline $\begin{array}{l}\text { Explanatory } \\
\text { Variable }\end{array}$ & $\begin{array}{l}\text { Parameter } \\
\text { estimate }\end{array}$ & $\begin{array}{l}\text { Standard } \\
\text { error }\end{array}$ & $\begin{array}{l}\text { t-statistic for } \mathrm{H}_{0} \text { : } \\
\text { parameter }=0\end{array}$ \\
\hline Intercept & -2.0996 & 12.4557 & -0.17 \\
\hline$p_{t-1}$ & 1.2640 & 0.1789 & 7.06 \\
\hline$p_{t-2}$ & -0.6210 & 0.2040 & -3.04 \\
\hline$p_{t-3}$ & 0.2546 & 0.1431 & 1.78 \\
\hline$\Delta f p_{t-1}$ & -0.4762 & 0.1768 & -2.69 \\
\hline$v_{a l}$ & -0.0889 & 0.1131 & -0.79 \\
\hline$r_{t-1}$ & -1.4208 & 1.9498 & -0.73 \\
\hline$c f_{t-1}$ & 0.0021 & 0.0030 & 0.71 \\
\hline$f c p_{t-1}$ & 0.2335 & 0.1214 & 1.92 \\
\hline $\operatorname{crnp}_{t-1}$ & 1.1682 & 0.8845 & 1.32 \\
\hline$c p l_{t-1}$ & 0.0143 & 0.0076 & 1.88 \\
\hline$l c p l_{t}$ & -0.0040 & 0.0115 & -0.35 \\
\hline
\end{tabular}

Note. Definitions of variables are provided in the Appendix.

ical regularities observable in the data. Our econometric forecasting models, then, are really just a convenient way of summarizing these empirical regularities.

The use of forecasts derived from econometric models as proxies for agents' expectations raises a secondary question. Should the expectation proxies be in-sample forecasts or out-of-sample forecasts; that is, forecasts based on regression coefficient estimates from the sub-sample that entirely pre-dates the week in which each 
forecast is made? The comparative virtues of these two alternative approaches have been debated for years. Our use of the in-sample approach has several precedents including the seminal paper by Barro (1977) and a recent paper by Borenstein and Shepard (1996). We note, however, that our replication of the analysis using out-ofsample forecasts from equation (4) produced results that did not support the models' hypothesis of a negative value for $a_{1}$ in equations (1) and (2). These forecasts were virtually uncorrelated with the actual price changes and the estimates of $a_{1}$ in equations (1) and (2) were insignificant. Finally, the assumption of perfect foresight is yet another approach sometimes used in modeling expectations. When the actual future values of price changes were used in equations (1), (2), and (3) in place of the expectations, the results were more strongly supportive of the hypothesis than the results obtained using in-sample forecasts from equations (4) and (5).

Having used forecasting equations (4) and (5) to develop proxies for the expectations, equations (1), (2), and (3) were estimated by ordinary least squares using a data set reduced, by the requirement of data on two lags of the dependent variable, to 65 useable observations. Consistency of OLS relies on the assumption of zero correlation between the explanatory variables and the contemporaneous error terms. In equation (1), for example, $Q M_{t}$, which is determined in period $t-2$, is regressed on a set of variables including several $\left(E_{t-2}\left[p_{t}-p_{t-1}\right], c r n p_{t-2}, f c p_{t-2}, r_{t-2}\right.$, and $\left.\operatorname{cssp}_{t-2}\right)$ that are also dated $t-2$. Simultaneity in the determination of the set of week $t-2$ variables could introduce correlations between the explanatory variables and $\varepsilon_{1 t}$, rendering OLS estimates inconsistent. To check for this possibility, we conducted Hausman tests of the pre-determinedness of week $t$ - 2 explanatory variables in equations (1) and (2), and week $t-1$ explanatory variables in equation (3). The method of these tests involves a comparison of OLS estimates with two-stage least squares estimates obtained using lagged values of explanatory variables as instruments. The hypothesis of pre-determinedness of the regressors could not be rejected at conventional significance levels for any of the three equations. Each equation was also tested for error-term serial correlation using the method applied to equations (4) and (5) and the hypothesis of no serial correlation could not be rejected for any one of the three equations. OLS estimation results are reported in Table 3 . The $t$-statistics reported in Table 3 are based on heteroscedasticity consistent standard errors calculated using the Newey-West procedure.

Our hypothesis implies negative values for the coefficients of the expected price change variables in equations (1), (2), and (3). In the case of equation (1)'s model of marketing agreement deliveries, the estimate of $a_{1}$ is negative and statistically significant with a marginal significance level of 0.001 (in a two-tailed test). To interpret the magnitude of the coefficient estimate, consider that the distribution, over the 67-week sample period, of the actual week-to-week price changes had a slightly negative mean and a range of roughly $\$-3.26 /$ cwt. to $\$ 3.55 /$ cwt. The standard deviation was approximately $\$ 1.47 /$ cwt. The distribution of the weekly total (four-plants-combined) marketing agreement delivery volume had a mean of 19,326 head and a standard deviation of 4,923 head. The estimate of $a_{1}$ in equation $(1)(-2,009.5)$, therefore, implies that an expected price increase of one sample standard deviation would trigger a decrease in weekly marketing agreement delivery volume of $0.60(=2,009.5 * 1.47 / 4,923)$ standard deviations. Thus, the effect of expected price changes on delivery scheduling incentives would appear to play a relatively significant role in explaining the week-to-week variation in marketing agreement delivery volume. 
Table 3. Results of Ordinary Least Squares Estimation of Equations (1), (2), and (3); the Captive Supply Delivery Volume Equations

\begin{tabular}{|c|c|c|c|}
\hline Explanatory variable & Equation (1) & Equation (2) & Equation (3) \\
\hline Intercept & $\begin{array}{l}33418 . \\
\quad(1.67)\end{array}$ & $\begin{array}{r}4586.1 \\
\quad(0.54)\end{array}$ & $\begin{array}{r}5134.1 \\
\quad(0.55)\end{array}$ \\
\hline$E_{t-2}\left[p_{t}-p_{t-1}\right]$ & $\begin{array}{r}-2009.5 \\
(-3.35)\end{array}$ & $\begin{array}{r}-786.09 \\
(-1.34)\end{array}$ & \\
\hline$E_{t-1}\left[p_{t}\right]-p_{t}-1$ & & & $\begin{array}{r}-788.29 \\
(-1.24)\end{array}$ \\
\hline$c r n p_{t-2}$ & $\begin{array}{r}-1346.3 \\
\quad(-0.63)\end{array}$ & & \\
\hline$f c p_{t-2}$ & $\begin{array}{c}57.500 \\
(0.24)\end{array}$ & & \\
\hline$r_{t-2}$ & $\begin{array}{r}-5029.1 \\
\quad(-1.82)\end{array}$ & $\begin{array}{r}120.09 \\
(0.07)\end{array}$ & \\
\hline $\operatorname{css} p_{t-2}$ & $\begin{array}{r}-138.25 \\
(-1.12)\end{array}$ & $\begin{array}{r}-351.97 \\
(-2.37)\end{array}$ & \\
\hline$r_{t-1}$ & & & $\begin{array}{l}-2.9317 \\
(-0.00)\end{array}$ \\
\hline $\operatorname{css} p_{t-1}$ & & & $\begin{array}{r}-332.08 \\
(-2.42)\end{array}$ \\
\hline$Q M_{t-1}$ & $\begin{array}{l}0.45394 \\
(3.59)\end{array}$ & & \\
\hline$Q M_{t-2}$ & $\begin{array}{l}0.27840 \\
(2.00)\end{array}$ & & \\
\hline$Q C_{t-1}$ & & $\begin{array}{l}0.47182 \\
(2.06)\end{array}$ & $\begin{array}{l}0.45005 \\
(1.94)\end{array}$ \\
\hline$Q C_{t-2}$ & & $\begin{array}{l}-0.10391 \\
(-1.25)\end{array}$ & $\begin{array}{l}-0.08562 \\
(-0.98)\end{array}$ \\
\hline$R^{2}$ & 0.565 & 0.332 & 0.333 \\
\hline
\end{tabular}

Dependent variable $=Q M_{t}$ (equation (1)) or $Q C_{t}$ (equations (2) and (3)). Number of observations $=65$.

Note. $t$-statistics, based on Newey-West heteroscedasticity-consistent standard errors, are given in parentheses.

Definitions of variables are provided in the Appendix.

In the cases of equations' (2) and (3) models of forward contract deliveries, the estimates of $a_{1}$ are both negative but with marginal significance levels of only 0.179 and 0.213 (in two-tailed tests), respectively. The mean and standard deviation of the sample's distribution of weekly forward contract delivery volume are 4,819 and 5,328, respectively. Thus, taking equation (2)'s point estimate of $a_{1}$ as representative, an expected price increase of one standard deviation would result in a $0.22(=786.09 * 1.47 / 5328)$ standard deviation decrease in the weekly forward contract delivery volume. In contrast to the marketing agreement case, there is weaker statistical support for the hypothesis in the forward contract case. The magnitude of the effect, if present, would also appear to be smaller. 


\section{Summary and Conclusions}

A number of papers in the agricultural economics literature have investigated the connection between the use of non-cash, or "captive" supply, procurement sources of fed cattle and the price in the residual cash market. One aspect of this inquiry is the characterization of the empirical relationship between captive supply delivery volume and cash market prices. Past work of this nature has focused on the correlation between contemporaneous levels of captive supply shipments and cash market prices. Considerable evidence of a negative correlation has been found: In weeks in which captive delivery volume is high, spot market price tends, other things equal, to be low.

With this report's econometric tests, we have sought evidence of a captive supply-cash price relationship of a different nature. The search was motivated by two stylized models of packers' and feeders' cattle delivery-scheduling decisions. The models predict a negative correlation between the volume of marketing agreement or forward contract deliveries in a given week, and an ex ante forecast of the change in price from its level of the previous week. Some work using the GIPSA-Texas Panhandle data revealed evidence of this kind of empirical regularity in the case of marketing agreement shipments. In the case of forward contract shipments, the statistical evidence is less convincing. For both cases, however, the findings are sensitive to the choice of a proxy for agents' expectations of price changes.

The impact of captive supplies on cash market prices for fed cattle is an issue of considerable interest to market participants and government policy makers. The robust empirical finding of a negative correlation between captive deliveries and price has attracted considerable attention, particularly from those who promote it as evidence that the use of captive supply procurement methods is responsible for low prices in the cash market. We believe, however, that the policy relevance of this empirical regularity is by no means clear. More careful examination of the underlying economic mechanisms of the fed cattle market is needed. This study falls short of a thorough analysis of those mechanisms. It does, however, raise a new possibility: The pattern of covariation, in weekly time series data, between captive supply delivery volume and cash market prices for fed cattle may be, in part, a reflection of the inter-temporal arbitrage opportunities available to packers and feeders in scheduling cattle delivery. It is not clear whether the observed negative correlation between the levels of price and captive shipments could be an artifact of these delivery timing incentives, but we believe that it is important that future studies of price dynamics in fed cattle markets take the role of delivery timing decisions into account.

\section{Appendix: Definitions of Variables}

$Q M_{t}\left(Q C_{t}\right)$ : The number of head of marketing agreement (forward contract) cattle delivered to the four plants in the GIPSA-Texas Panhandle study in week $t$. (Head)

$p_{t}$ : The spot market price of cattle in the relevant regional market in week $t$. For each reporting day in week $t$, we obtained the AMS reported weighted-average price of steers, 1,100-1,250 lb. live weight category, in lots grading 35-65\% Select or Choice, for the Western Oklahoma-Texas Panhandle region; and the number of head upon which each reported price is based. $p_{t}$ is then defined as the head-weighted average of daily average prices for reporting days in week $t$. (\$/cwt., live weight basis). 
$\Delta f p_{t}$ : The change in the price of week $t^{\prime}$ s "nearby" Chicago Mercantile Exchange live cattle futures contract from the first reporting day of week $t-1$ to the first reporting day of week $t$. The nearby contract for week $t$ is the earliest contract still trading in week $t$ unless its end-of-trade date occurs during week $t$. In that event, the next contract is taken as the nearby contract. (\$/cwt.)

$v_{a l}$ : Simple average of AMS reported box beef cutout values for "light Choice," "heavy Choice," "light Select," and "heavy Select" for week $t$. (\$/cwt.)

$r_{t}$ : An average of daily values for the 6-month Treasury bill rate in secondary markets for days in week $t .(\%)$

$c f_{t}$ : The number of cattle on feed in week $t$ in Texas feed yards with capacity of 1,000 head or more. The National Agricultural Statistics Service (NASS) reports cattle on feed on the first day of each month. These values were assigned to the weeks containing the months' first days. Figures for the remaining weeks were estimated by linear interpolation. (1,000 head)

$c p l_{t}$ : The number of cattle placed on feed in week $t$ in Texas feed yards with capacity of 1,000 head or more. NASS reports cattle placements on a monthly basis only. Weekly cattle placements were estimated using the assumption that the number placed during each month was uniformly distributed across days of the month. (1,000 head)

$l c p l_{t}$ : A simple average of weekly cattle placements (values of cpls) for weeks 20, 21, 22, and 23 weeks prior to week $t$. (1,000 head)

$f_{c p_{t}}$ : AMS reported price of feeder cattle (medium and large frame, \#1, 600-650 lbs.) in the Amarillo auction market in week $t$. (\$/cwt.)

$c r n p_{t}$ : The price of \#2 yellow corn in the "Triangle" area (Plainview to Canyon to Farwell Texas). A simple average of daily prices for days in week $t$. $(\$ /$ bu.)

$\operatorname{cssp}_{t}$ : AMS reported boxed beef cutout spread, Choice-Select, 500-700 lbs. yield grades 2-3, for week $t$. (\$/cwt.)

\section{Acknowledgments}

This paper is based on a part of a larger research report, "Econometric Analysis of Fed Cattle Procurement in the Texas Panhandle," written in fulfillment of Cooperative Agreement No. 98-PPD-01, USDA, Grain Inspection, Packers and Stockyards Administration (GIPSA). The authors gratefully acknowledge financial support from GIPSA and helpful comments by DeeVon Bailey, John Lawrence, Alan Love, Richard Sexton, and two anonymous referees. The opinions expressed in this paper are those of the authors and do not necessarily reflect the views of GIPSA or USDA.

\section{References}

Azzam, A. (1998). Captive supplies, market conduct, and the open market price. American Journal of Agricultural Economics , 80, 76-83.

Barro, R.J. (1977). Unanticipated money growth and unemployment in the United States. American Economic Review , 67, 101-115.

Borenstein, S., \& Shepard, A. (1996). Dynamic pricing in retail gasoline markets. RAND Journal of Economics , 27, 429-451.

Elam, E. ( 1992). Cash forward contracting vs. hedging of fed cattle, and the impact of cash contracting on cash prices. Journal of Agricultural and Resource Economics , 17, 205-217.

Greene, W. ( 2000). Econometric analysis (4th ed.). Upper Saddle River, NJ: Prentice Hall. 
Hausman, J. ( 2000). Comments to the USDA Captive Supply Forum. Retrieved May 28, 2004, from http://www.usda.gov/gipsa/psp/issues/forum/hausman.htm

Hayenga, M., \& O'Brien, D. (1992). Packer competition, forward contracting price impacts, and the relevant market for fed cattle. In W. Purcell (Ed.), Pricing and coordination in consolidated livestock markets: Captive supplies, market power, and IRS hedging policy (pp. 134158). Blacksburg VA: Virginia Tech University, Research Institute on Livestock Pricing.

Love, H., \& Burton, D. ( 1999). A strategic rationale for captive supplies. Journal of Agricultural and Resource Economics , 24, 1-18.

Schroeder, T. ( 2000). Reasons for and impacts of changing fed cattle procurement practices. Retrieved May 28, 2004, from http://www.usda.gov/gipsa/psp/issues/forum/ schroeder.pdf.

Schroeder, T., Jones, R., Mintert, J., \& Barkley, A. ( 1993). The impact of forward contracting on fed cattle transaction prices. Review of Agricultural Economics , 15, 325-337.

Schroeter, J., \& Azzam, A. (1999). Econometric analysis of fed cattle procurement in the Texas Panhandle. Report submitted to United States Department of Agriculture; Grain Inspection, Packers and Stockyards Administration. Retrieved May 28, 2004, from http://www.usda.gov/gipsa/psp/issues/txpeer/reportindex.htm.

United States Department of Agriculture; Grain Inspection, Packers and Stockyards Administration ( 2002). Captive Supply of Cattle and GIPSA's Reporting of Captive Supply. Retrieved May 28, 2004, from http://www.usda.gov/gipsa/pubs/captive_supply/captive.htm.

Ward, C., Koontz, S., Dowty, T., Trapp, J., \& Peel, D. ( 1999). Marketing Agreement Impacts in an Experimental Market for Fed Cattle. American Journal of Agricultural Economics , 81, 347-358.

Ward, C., Koontz, S., \& Schroeder, T. ( 1996). Short-run captive supply relationships with fed cattle transaction prices. In Role of captive supplies in beef packing (pp. 5-96). USDA GIPSA-RR 96-3, Washington, DC.

John R. Schroeter is Associate Professor, Department of Economics, Iowa State University. He received his Ph.D. from the University of Minnesota, Twin Cities, in 1981. The majority of his research is in the area of empirical industrial organization.

Azzeddine Azzam is Professor and Director of the Center of Agricultural and Food Industrial Organization, Department of Agricultural Economics, University of Nebraska-Lincoln. He received his Ph.D. from the University of Nebraska-Lincoln in 1985. His research interest is in empirical industrial organization with a focus on livestock markets. 